\title{
EJNSO
}

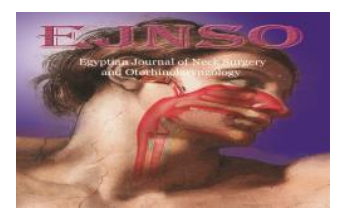

\section{Gender Differences in Normal Swallow}

Ahlam A. Nabieh, Ahmed M. Emam, Eman M. Mostafa and Rasha M. Hashem

Phoniatrics unit, ENT department, Sohag University

\begin{abstract}
Introduction: Swallowing is a complex neuromuscular task executed by humans. It requires precise coordination between 34 pairs of muscles in just over one second. The rapid sequential and overlapping motions characterizing adult human swallowing behavior were better appreciated with the introduction of radiography, and especially video radiography. There are data suggesting that women swallow liquids at a lower flow rate and ingest smaller volumes in each swallow than men.

Aim of the work: To assess the physiological difference between males and females in oropharyngeal and esophageal phases of swallowing in normal middle-aged individuals.

Patients and Methods: Cross sectional study, included 30 healthy volunteers (15 males \& 15 females) with normal swallowing, whose age ranged from 18-45 yrs. This study was conducted in Sohag University Hospital, Phoniatric Unit. All volunteers were subjected to Video-Fluroscopic Swallowing Study (VFSS) in sitting position. Oral transit time (OTT), Pharyngeal transient time (PTT), Oropharyngeal transient time, Esophageal transit time (ETT), Total swallow time (TST) were measured. Also, hyoid peak was calculated.

Results: There were no significant difference between males and females swallowing in both fluid and solid boluses.

Conclusion: This study provided insights into normal swallowing physiology and defines measurement alternatives for evaluation of the dysphagic patients.
\end{abstract}

Keywords: Swallowing, Gender, VFSS.

\section{$\underline{\text { Introduction }}$}

Swallowing is a combination of sequences and multiple stages which mediated by complex sensory and motor signals to the oral and pharyngolaryngeal regions. The goal of swallowing is bolus propulsion to the esophagus while protecting the airway (1). Swallowing process occurs about one thousand times per day to transport saliva and to transport voluntarily food from the mouth to the stomach ${ }^{(2)}$.

The swallowing process can be divided into the following 3 phases: the oral phase, pharyngeal phase, and esophageal phase, each of which corresponds to the location of the food bolus in the swallowing apparatus. The oral phase is further subdivided into two sub-phases (oral preparatory and oral propulsive phases) ${ }^{(3)}$. The oral phase is the only voluntary phase and triggers the subsequent involuntary pharyngeal and esophageal phases ${ }^{(4)}$.

Swallowing is influenced by the volume, consistency, and temperature of the bolus swallowed ${ }^{(5)}$. It is also influenced by anatomic characteristics, behavior, and the integrity of the muscles and nerves involved ${ }^{(6)}$.

In the past years, there has been increasing interest in differences in swallowing function in normal males 
and females ${ }^{(7)}$. The study showed that females swallow liquid at a lower flow rate and ingest smaller volumes in each swallow than males ${ }^{\left({ }^{8}\right)}$. These results were obtained with the swallowing drinking test, which is easy to perform and quantifies swallowing dynamics (9).

The physiologic components of the swallowing process overlap and are interdependent as the bolus traverses the regional phases (oral, pharyngeal, esophageal) and has led clinicians to attempt assessment of the physiology of the swallowing, rather than reporting abnormality of a given phase. Moreover, the physiology will be the target of swallowing rehabilitation, and it is critical that these targets be identified before development of the treatment strategy ${ }^{(5)}$.

The current study was designed to determine if there are changes that occur during swallowing as a result of gender difference. Definitions of any differences on swallow in normal men and women should help to tailor more effective treatments for the oldest dysphagic persons of each sex.

\section{Aim of the work:}

To assess the physiological difference between males and females in oropharyngeal and esophageal phases of swallowing.

\section{Patients and Methods:}

Design: Cross sectional study.

\section{Patients:}

This study included 30 healthy volunteers divided into two groups; 15 males and 15 females.

\section{Inclusion criteria:}

All healthy individuals whose age range between (18-45yrs) proved by history and clinical examination.

\section{Exclusion criteria:}

Patient with history of dysphagia, gastroesophageal reflux disease (GERD) symptoms, neurological musculoskeletal disorders and history of any oropharyngeal structural or functional abnormalities.

\section{Methods:}

All individuals were subjected to videofluroscopic swallow study (VFSS). The apparatus used for the procedure was videofluroscopy (PHILIPS type $984850051001 \quad$ SN07001508 Duo Diagnost) which is a radiological equipment with image display connected to a DVD that allows recording for subsequent analysis, including use of slow motion for detailed investigation. The examination session consumed $3 \pm 1$ min. The VFSS took place in a standard radiology fluoroscopy suite. The fluoroscope was activated for a few seconds before and after the administration of the barium substances.

All subjects were imaged in an upright seated position. They were asked to establish a comfortable head position making sure that the head is not tilted toward either shoulder nor flexed or extended. In both positions the subject was examined in lateral view and antroposterior view.

\section{In the lateral view:}

The visualization field included the lips anteriorly, nasal cavity superiorly, cervical spinal column posteriorly, and the entire pharyngoesophageal segment (PES) inferior. The larynx was in full view within this visualization field. The fluoroscope was deactivated shortly after the bolus tail had exited the cervical esophageal region.

\section{In the antro-posterior view:}

The visualization field included the entire pharyngoesophageal segment (PES) superiorly then the fluoroscopic tube moved during examination to enable the examiner for full viewing of the esophagus till the lower esophageal sphincter and the stomach viewed. In this view Esophageal transit time (ETT) calculated. 
The total bolus number administrated during examination was four boluses. The protocol include intake of two liquid boluses and two solid boluses (one liquid bolus and one solid in each view). The liquid bolus consisted of 10 $\mathrm{ml}$ (1:1 consistency) and solid bolus (cookies soaked in liquid barium).

a-Some durational measurement obtained from the videofluoroscopic assessment as:

1-Oral transit time (OTT): Is the duration measure of bolus movement through the oral cavity. The end of oral stage is determined as the moment when the head of the bolus passes the ramus of the mandible.

2-Pharyngeal transient time (PTT):

Frames were counted from the point where the swallow was triggered to the point where the bolus passed the cricopharyngeal segment. The point where the swallow was triggered was marked by the bolus head passing the ramus of the mandible. The end of the pharyngeal stage was determined by the passing of the entire bolus through the cricopharyngeal segment, which was determined as the segment of tissue at the same horizontal level of the vestibule or opening to the larynx ${ }^{(10)}$.

3-Oropharyngeal transient time: as interval between the bolus at incisors to the offset of UES opening (11).

4- Esophageal transit time (ETT): Interval from the bolus passing the cricopharyngeus (UES) to the bolus passing the LES. It is calculated from the bolus tail crossing the UES till it reach the LES (12). ETT assessed during anterior-posterior vie

5-Total swallow time (TST):

Calculated by adding oropharyngeal swallow time and ETT.

b-Hyoid peak calculation:

For calculation of hyoid peak, two frames obtained (the 1st one at the onset of hyoid bursts\& the 2 nd one at the end of hyoid bursts). The frames imported to Image $J$ software, using a coordinate system with an origin at the anteriorinferior corner of the C4-vertebrae and vertical axis defined by a line running from the origin upwards through the anterior-inferior corner of the $\mathrm{C} 2$ vertebrae (see Fig 1). The distance between the anterior-inferior corners of the $\mathrm{C} 2$ and $\mathrm{C} 4$ vertebrae also served as an anatomical scalar to enable us to control for differences in the size of the pharynx across participants during measurements of hyoid movement distance $^{(13)}$.

\section{Results:}

Thirty healthy volunteers ( 15 males \& 15 females) were recruited in the study, with mean age $\pm \operatorname{SD}(30.6 \pm 8.6)$.

There was no significant difference between males and females in hyoid peak elevation \& the duration of all phases of swallowing during studying both fluid and solid boluses (table $1 \&$ 2). 
Nabieh et al. 2018

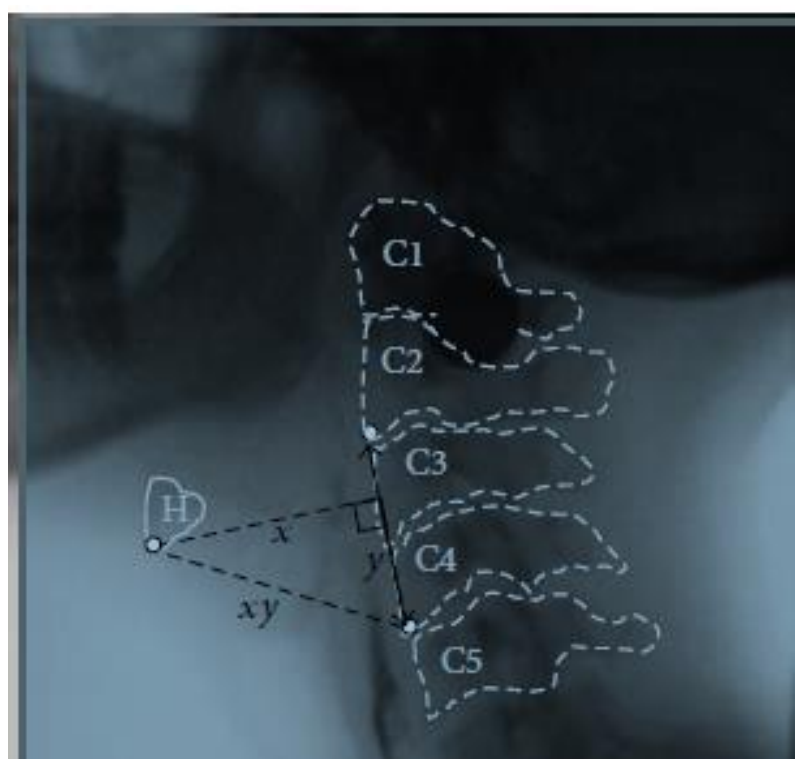

Figure (1) Lateral view videofluoroscopic image, showing the hyoid $(\mathrm{H})$ at maximum excursion and the anatomical points used for measurement in a coordinate system with the origin located at the anterior-inferior corner of $\mathrm{C} 4$ and the vertical axis running in a line up from the origin through the anterior-inferior corner of C2 (Extracted from Nagy et al. ${ }^{17}$ ).

Table (1). Difference between males \& females during fluid bolus swallowing.

\begin{tabular}{|c|c|c|c|c|}
\hline \multicolumn{2}{|l|}{ Variable } & Mean \pm SD & T value & $P$ value \\
\hline \multirow[t]{2}{*}{ OTT } & Males & $1.87 \pm 0.62$ & \multirow[b]{2}{*}{0.033} & \multirow[b]{2}{*}{0.97} \\
\hline & Females & $1.88 \pm 0.82$ & & \\
\hline \multirow{2}{*}{ PTT } & Males & $0.69 \pm 0.14$ & \multirow[b]{2}{*}{1.435} & \multirow[b]{2}{*}{0.16} \\
\hline & Females & $0.75 \pm 0.11$ & & \\
\hline \multirow{2}{*}{$\begin{array}{l}\text { Oropharyngeal } \\
\text { transient time }\end{array}$} & Males & $2.56 \pm 0.61$ & \multirow[b]{2}{*}{0.291} & \multirow[b]{2}{*}{0.77} \\
\hline & Females & $2.65 \pm 0.87$ & & \\
\hline \multirow[t]{2}{*}{ ETT } & Males & $6.85 \pm 2.08$ & \multirow[b]{2}{*}{0.852} & \multirow[b]{2}{*}{0.40} \\
\hline & Females & $6.24 \pm 1.89$ & & \\
\hline \multirow{2}{*}{ TST } & Male & $9.43 \pm 2.06$ & \multirow[b]{2}{*}{0.668} & \multirow[b]{2}{*}{0.51} \\
\hline & Females & $8.89 \pm 2.31$ & & \\
\hline \multirow{2}{*}{$\begin{array}{l}\text { Superior Hyoid } \\
\text { Elevation }\end{array}$} & Males & $31.52 \% \pm 16.15$ & \multirow[b]{2}{*}{1.47} & \multirow[b]{2}{*}{0.163} \\
\hline & Females & $40.09 \% \pm 14.11$ & & \\
\hline \multirow{2}{*}{$\begin{array}{l}\text { Anterior Hyoid } \\
\text { Elevation }\end{array}$} & Males & $35.01 \% \pm 14.27$ & \multirow{2}{*}{0.73} & \multirow{2}{*}{0.47} \\
\hline & Females & $39.1 \% \pm 14.11$ & & \\
\hline
\end{tabular}


Table (2): Difference between males \& females during solid bolus swallowing.

\begin{tabular}{|c|c|c|c|c|}
\hline \multicolumn{2}{|l|}{ Variable } & Mean \pm SD & T value & $P$ value \\
\hline \multirow{2}{*}{ OTT } & Males & $7.83 \pm 4.28$ & \multirow[b]{2}{*}{0.038} & \multirow[b]{2}{*}{0.970} \\
\hline & Females & $7.78 \pm 3.66$ & & \\
\hline \multirow[t]{2}{*}{ PTT } & Males & $0.59 \pm 0.17$ & \multirow[b]{2}{*}{0.045} & \multirow[b]{2}{*}{0.964} \\
\hline & Females & $0.59 \pm 0.09$ & & \\
\hline \multirow{2}{*}{$\begin{array}{l}\text { Oropharyngeal } \\
\text { swallow time }\end{array}$} & Males & $8.44 \pm 4.24$ & \multirow[b]{2}{*}{0.053} & \multirow[b]{2}{*}{0.958} \\
\hline & Females & $8.36 \pm 3.71$ & & \\
\hline \multirow{2}{*}{ ETT } & Males & $14.82 \pm 7.27$ & \multirow[b]{2}{*}{0.244} & \multirow[b]{2}{*}{0.809} \\
\hline & Females & $14.09 \pm 8.67$ & & \\
\hline \multirow{2}{*}{ TST } & Males & $23.54 \pm 8.99$ & \multirow[b]{2}{*}{0.250} & \multirow[b]{2}{*}{0.804} \\
\hline & Females & $22.66 \pm 9.18$ & & \\
\hline \multirow{2}{*}{$\begin{array}{l}\text { Superior Hyoid } \\
\text { Elevation }\end{array}$} & Males & $43.3 \% \pm 19.5$ & \multirow[b]{2}{*}{0.27} & \multirow[b]{2}{*}{0.73} \\
\hline & Females & $35.6 \% \pm 15.4$ & & \\
\hline \multirow{2}{*}{$\begin{array}{l}\text { Anterior Hyoid } \\
\text { Elevation }\end{array}$} & Males & $37.35 \% \pm 13.01$ & \multirow[b]{2}{*}{1.06} & \multirow[b]{2}{*}{0.31} \\
\hline & Females & $35.07 \% \pm 14.6$ & & \\
\hline
\end{tabular}

\section{Discussion:}

The study showed no significant difference between males and females in the duration of all phases of swallowing in both fluid and solid boluses. It is supported by Dantas et al. ${ }^{(12)}$ in a study on 30 volunteers (18 males \& 12 females) during studying $10 \mathrm{ml}$ of fluid barium \& $10 \mathrm{ml}$ of paste material. During studying $10 \mathrm{ml}$ fluid bolus, the results show no significant difference between males and females in OTT, PTT, oropharyngeal transient time, pharyngeal clearance \& UES opening. Yet, the pharyngeal clearance and UES opening time show significant difference for $10 \mathrm{ml}$ paste bolus as they were longer in women than in men $(p=0.01)$. On the other hand, during studying $5 \mathrm{ml}$ fluid bolus and $5 \mathrm{ml}$ paste bolus, the oral transit and pharyngeal clearance and oropharyngeal transient time were longer in females than in males $(\mathrm{P}$ value $<0.05, \quad \mathrm{P}$ value $<0.03$ respectively). The study explained these results by anatomic differences between males and females as the diameter of the pharynx differs between them, with females having smaller head and neck anatomy than males ${ }^{(14)}$. The authors also referred to a smaller pharyngeal and UES area of females, in addition to smaller and the slower oropharyngeal transit than observed in males to accommodate the safe passage of the bolus through the pharynx into the esophagus ${ }^{(15)}$.

The results of this study don't coincide with Alvess et al. ${ }^{(8)}$. The latter study examined thirty-six males \& seventy-five females in which they swallowed in triplicate $50 \mathrm{~mL}$ of water at $4^{\circ} \mathrm{C}$ while precisely timed. The a) inter-swallow interval, b) swallowing velocity are calculated. Comparisons of males and women revealed a shorter inter-swallow interval, slower swallowing velocity and lower volume capacity in women $(P<0.05)$. The study explained the difference between males and females might be related to a larger oral and pharyngeal cavity in men, allowing a large bolus volume to be swallowed. 
It was not clear why there was no significant difference in superior and anterior hyoid peak elevation regard to the gender. Our result doesn't coincide with Perry et al ${ }^{(16)}$ study who assessed the displacement of the hyoid bone of twelve adults volunteers whose age range between (19 - 27 yrs). Subjects were recorded swallowing $7 \mathrm{cc}$ of liquid barium in the upright position. They demonstrated variations in hyoid displacement, and bolus movement through the pharynx with respect to the volunteers' gender. Males demonstrated a greater amount of superior and anterior displacement of the hyoid bone compared to females. This might be explained by looking at the differences in the size of the craniofacial anatomy for the individuals in the study. The difference between our result and Perrys' et al study may be due to the difference of the age range of the selected group and the amount of administrated boluses between the two studies.

\section{Conclusion:}

This study intended to identify clinically significant measures that can be made from a swallow study and to report their normative values in both genders. It provides insight into normal swallowing physiology and define measurement alternatives for evaluation of the dysphagic patient.

\section{References:}

1. Kahrilas, P.J., Dodds, W.J. \& Hogan, W.J.(1988). The effect of peristaltic dysfunction on esophageal volume clearance. Gastroenterology, 94,73-80.

2. Dodds, J.W. (1989).The physiology of swallowing. Dysphagia, 3,171-178.

3. Hiiemae, K.M. \& Palmer, J.B (2003). Tongue movements in feeding and speech. Crit Rev Oral Biol Med ; 14:413-429.

4. Miller, A (2013): Overview of deglutition and swallowing. In: Shaker R, Belafsky PC, Postma GN, editors. Principles of Deglutition: A Multidisciplinary Text For Swallowing and its Disorders. New York: Springer Science \& Business Media;. p. 3-17.

5. Adeleye, B. Rachel, C. ( 2007). Comparison of the rheological properties of ready-to-serve and powdered instant food-thickened beverages at different temperatures for dysphagic patients. J Am Diet Assoc; 107:1176-82.

6. Bass, N.H. (1997). The neurology of swallowing. In: Groher ME, editor. Dysphagia-diagnosis and management. 3rd ed. Boston: Butterworth-Heinemann; p. 7-35.

7. Hiss, S. G., Treole, K., \& Stuart, A. (2001). Effects of age, gender, bolus volume, and trial on swallowing apnea duration and swallow/respiratory phase relationships of normal adults. Dysphagia, 16, 128-135.

8. Alves, L.M., Casssiani, R.A., Santos, C.M., Dantas, R.O.(2007). Gender effect on the clinical measurement of swallowing. Arq Gastroenterol.

44:227-9.

9. Chee, C., Arshad, S., Singh, S., Mistry, S., Hamdy, S.(2005). The influence of chemical gustatory stimuli and oral anaesthesia on healthy human pharyngeal swallowing. Chem Senses. 30:393-400.

10. Logemann, J.A. (1998). Evaluation and treatment of swallowing disorders. Measurment of swallowing and intervention strategies. 2nd editition ,Austin, (TX):Pro-Ed.

11. Robbins, J., Hamilton, J. W., Lof, G. L., \& Kempster, G. B. (1992). Oropharyngeal swallowing in normal adults of different 
ages. Gastroenterology, 103(3), $\quad$ 823829.

12. Dantas, R. O., de Aguiar Cassiani, R., Dos Santos, C. M., Gonzaga, G. C., Alves, L. M. T., \& Mazin, S. C. (2009). Effect of gender on swallow event duration assessed by videofluoroscopy. Dysphagia, 24(3), 280-284.

13. Molfenter, S. M., \& Steele, C. M. (2014). Use of an anatomical scalar to control for sex-based size differences in measures of hyoid excursion during swallowing. Journal of Speech, Language, and Hearing Research, 57(3), 768-778.

14.Trawitzki, L. V., Dantas, R. O., Mello-Filho, F. V., \& Elias-Júnior, J.
(2006). Effect of treatment of dentofacial deformity on masseter muscle thickness. Archives of oral biology, 51(12), 1086-1092.

15. Glucksmann, A. (1981). Sexual dimorphism in human and mammalian biology and pathology. Academic Press.

16. Perry, J.L., Bae, Y. and Kuehn, D. P. (2012). Effect of Posture on Deglutitive Biomechanics in Healthy Individuals. Dysphagia , 27:70-80.

17. Nagy, A., Molfenter, S. M., Péladeau-Pigeon, M., Stokely, S., \& Steele, C. M. (2014). The effect of bolus volume on hyoid kinematics in healthy swallowing. BioMed research international, 2014. 